\title{
Reduced Occurrence Rate of Acute Anterior Uveitis in Ankylosing Spondylitis Treated with Golimumab - The GO-EASY Study
}

\author{
Rianne E. van Bentum, Sjoerd C. Heslinga, Michael T. Nurmohamed, Andreas H. Gerards, \\ Ed N. Griep, Charlotte B.J.M. Koehorst, Marc R. Kok, Anna M. Schilder, Marijn Verhoef, \\ and Irene E. van der Horst-Bruinsma
}

\begin{abstract}
Objective. Acute anterior uveitis (AAU) is common in ankylosing spondylitis (AS). Golimumab (GOL), a tumor necrosis factor- $\alpha$ inhibitor (TNFi), has proven to be effective in the treatment of AS. To date, the effect of GOL on the incidence of AAU in AS is unknown. The objective was to study the AAU occurrence rate in patients with AS during GOL treatment and secondarily, the efficacy of GOL in daily clinical practice.

Methods. The study was a multicenter prospective study in a real-world setting in patients with AS who were treated with GOL for 12 months. The occurrence of AAU was assessed in the year before the initial TNFi treatment and during GOL treatment and calculated for the period at risk for a new AAU. Measures for disease activity [Ankylosing Spondylitis Disease Activity Score (ASDAS)] and treatment response [Assessment of Spondyloarthritis international Society (ASAS20 score)] were collected.

Results. In total, 93 patients (65\% male, 55\% TNFi-naive, 27\% history of AAU) were included, with a median disease duration of 7 years and ASDAS score of 3.1. During GOL treatment, the AAU occurrence rate was reduced from 11.1 to 2.2 per 100 patient-years (rate-ratio $0.20,95 \%$ CI $0.04-0.91$ ). After 3 months of treatment, $41 \%$ of the patients experienced a clinically important improvement of the ASDAS score $(\mathrm{p}<0.001)$ and $36 \%$ an ASDAS20 response $(\mathrm{p}<0.001)$. At month $12,49 \%$ had achieved an ASAS20 response $(\mathrm{p}<0.001)$.

Conclusion. In AS, the AAU occurrence rate and disease activity decreased significantly during GOL treatment. Therefore, GOL can be considered a good choice in patients with AS who need a TNFi, especially in cases of recurrent AAU. (EudraCT number: 2012-002458-21) (First Release November 1 2018; J Rheumatol 2019;46:153-9; doi:10.3899/jrheum.180312)
\end{abstract}

Key Indexing Terms:

SPONDYLOARTHRITIS

ANKYLOSING SPONDYLITIS

ANTERIOR UVEITIS

IRIDOCYCLITIS

TUMOR NECROSIS FACTOR-A

MONOCLONAL ANTIBODIES

the Netherlands; I.E. van der Horst-Bruinsma, MD, PhD, Department of Rheumatology, Amsterdam Rheumatology and immunology Center, locations Reade and VU University Medical Center. Dr. van Bentum and Dr. Heslinga contributed equally to this work.

Address correspondence to Dr. I.E. van der Horst-Bruinsma, Amsterdam Rheumatology and Immunology Center, VU University Medical Center, Room 3A47, P.O. Box 7057, 1007 MB Amsterdam, the Netherlands. E-mail:ie.vanderhorst@vumc.nl

Full Release Article. For details see Reprints and Permissions at jrheum.org

Accepted for publication August 16, 2018.

Ankylosing spondylitis (AS) is a chronic inflammatory disease characterized by inflammation of the sacroiliac joints and spinal column, causing severe pain and stiffness ${ }^{1}$. Extraarticular comorbidity is common in $\mathrm{AS}^{2}$. Acute anterior uveitis (AAU) is the most frequent occurring manifestation, eventually affecting about every third patient with AS, often more than once ${ }^{3}$.

AAU most frequently occurs unilaterally; however, both

Personal non-commercial use only. The Journal of Rheumatology Copyright @ 2019 . All rights reserved. 
eyes can be affected simultaneously ${ }^{3}$. AAU causes severe pain, redness, photophobia, and blurred vision and is associated with a significant decrease in quality of life ${ }^{4}$. The inflammation may subside without medical intervention, but attacks should always be investigated and treated by an ophthalmologist, with primarily local (and sometimes systemic) corticosteroids. Recurrent AAU may lead to complications in about $20 \%$ of the patients, including posterior synechiae, glaucoma, cataract, and although very rarely, macular edema. Eventually, $4 \%$ of patients with AS experience a permanent decrease in visual acuity ${ }^{3,5,6}$. Because of its high recurrence rate, especially in HLA-B27positive patients, AAU is one of the most significant burdens for patients with AS.

The pathophysiologic similarities between AS and AAU have been extensively studied. Both AS and AAU are associated with the HLA-B27 genotype but may also occur in HLA-B27-negative patients ${ }^{7}$. Also, other genes associated with both AS and AAU have been identified, and indicate an important role of tumor necrosis factor- $\alpha(\mathrm{TNF}-\alpha)$ in the chronic inflammatory process of these diseases ${ }^{8,9}$.

Control of AS disease activity has improved considerably since the introduction of TNF- $\alpha$ inhibitors $(\mathrm{TNFi})^{10}$. Moreover, some TNFi appear to reduce the occurrence of AAU in AS, in contrast with nonsteroidal antiinflammatory drugs (NSAID), that are the first treatment step in AS but do not prevent or treat AAU ${ }^{11,12}$. The effect of monoclonal antibodies (adalimumab, infliximab) has been well established, with reported changes in AAU ranging from 51.8 to 21.4 attacks per 100 patient-years (PY), to 15.6 to 3.4 per 100 $\mathrm{PY}^{1,11,12,13}$. Recently, the 4-year followup data of a phase III trial also showed promising results for certolizumab ${ }^{14}$. The effect of the TNF receptor fusion protein etanercept is still under debate because several studies reported an unchanged or even elevated risk of $\mathrm{AAU}^{1,11,15,16}$. It is still a matter of debate whether patients who develop their first AAU during TNFi treatment, even when other disease activity measurements of AS are low, in fact react paradoxically to a TNFi or whether these attacks are part of the normal pattern and respond insufficiently to $\mathrm{TNFi}^{17,18,19,20}$.

The TNFi golimumab (GOL) was approved for the treatment of AS in 2009, after it was proven to be both effective and safe in a large phase III controlled trial ${ }^{21}$. The first reports on the occurrence of AAU during GOL treatment seemed positive, but only a few studies have been performed and the included patient numbers are small ${ }^{22,23}$. Further, data on the efficacy of GOL in routine daily practice are currently still lacking.

Our current study is a prospective, history-controlled, multicenter study in a real-world setting, comparing the annual incidence rate of AAU in patients with AS when treated with GOL to the year before the initiation of TNFi therapy. The secondary objective was to assess the effectiveness and safety of GOL on AS disease activity in routine daily practice.

\section{MATERIALS AND METHODS}

Patients. Patients with AS were enrolled consecutively between December 2012 and April 2014 at the Amsterdam Rheumatology and Immunology Center (locations VU University Medical Centre and Reade) and 9 large outpatient rheumatology clinics in the Netherlands. Patients were recruited if they were prescribed GOL in routine daily practice. Inclusion criteria were a previous diagnosis of AS according to the 1984 modified New York criteria for $\mathrm{AS}^{24}$, prescription of $\mathrm{GOL}$ in accordance with the international consensus of the Assessment of Spondyloarthritis international Society (ASAS) for initiating TNFi in $\mathrm{AS}^{25}$, age of 18 years or older, and the availability of historical medical data for at least 12 months prior to the start of the first TNFi. Exclusion criteria were the use of an investigational biological or chemical agent within 30 days or 2 half-lives (whichever was the longest) of screening, or prior use of GOL. All patients were treated with GOL 50 $\mathrm{mg}$ through subcutaneous injection once a month for 12 consecutive months. The first dose was administered at the baseline visit. Other baseline medication, except for other TNFi, was continued. Study visits were performed at 1,3,6,9, and 12 months after treatment initiation, with a total followup period of 12 months. Full local ethical approval was obtained from the medical ethics committee of the Slotervaart hospital and Reade (approval number NL40935.048.12/P1232). The EudraCT number is 2012-002458-21. All participating patients gave written informed consent.

Outcome measures. The primary outcome measure was the occurrence of AAU attacks in the first 12 months of GOL treatment, in comparison to the 12 months before the first TNFi (being either the year before starting GOL, in TNFi-naive patients, or the 12 months before the first treatment with a $\mathrm{TNFi}$, in TNFi-experienced patients). The secondary outcome measures were (changes in) disease activity measures during GOL treatment.

Measures. At baseline, measures collected were the demographics, medical history, treatment history, current disease status, and history of extraarticular manifestations (EAM). A review of the medical records and a physical examination were done. Both at baseline and at 12 months, ophthalmology records were checked for the (historic) presence of AAU. In case of doubt, the treating ophthalmologist was contacted to confirm the diagnosis of AAU.

At 1,3,6, 9, and 12 months of treatment, the patients were assessed by a physician or research nurse, evaluating the disease status, concomitant medication, and the presence of EAM. Physical examination, including height, weight, and blood pressure, was performed at every visit according to standard hospital procedures. Laboratory measurements included C-reactive protein (CRP) and erythrocyte sedimentation rate (ESR).

The following AS-specific variables were collected at every visit: the tender and swollen joint count, Maastricht Ankylosing Spondylitis Enthesitis Score, Bath Ankylosing Spondylitis Metrology Index, Ankylosing Spondylitis Disease Activity Score-CRP (ASDAS-CRP), the Bath Ankylosing Spondylitis Disease Activity Index (BASDAI), Bath Ankylosing Spondylitis Functional Index (BASFI), patient disease activity score (numerical rating scale, patient-NRS), physician disease activity score (physician-NRS), Bath Ankylosing Spondylitis Global score, and the AS Quality of Life questionnaire (ASQoL) ${ }^{26-32}$. Also, the occurrence of (serious) adverse events (SAE) was recorded.

Improvement in disease activity was defined as an improvement of the ASDAS score, with a clinically relevant improvement defined as a $\geq 1.1$ units and a major improvement as $\mathrm{a} \geq 2.0$ units $^{33}$. Response to treatment was defined as an improvement in the ASAS20 score of $>20 \%$ and a reduction of $>10$ units in at least 3 out of the 4 domains (patient-NRS, pain, BASFI, and the mean of BASDAI question 5 and 6$)^{34}$

Statistical analysis. Data are presented as mean $( \pm \mathrm{SD})$, median (with first and third quartile), or percentages. The baseline and GOL efficacy data and analyses were performed only for the patients who used GOL for at least 3 months, did not miss more than 1 dose in the first 3 months, had followup data available for the first 3 months, and did not use another biological agent (including other TNFi) within 1 year after the first GOL dose. Patients who discontinued treatment after 3 months were not considered as having ended study participation prematurely and were included for followup by partici-

Personal non-commercial use only. The Journal of Rheumatology Copyright @ 2019. All rights reserved. 
pating in the scheduled visits. Safety data are presented for all enrolled patients who took at least 1 dose of GOL.

For the analyses of changes in AAU, the period (in months) of active AAU was subtracted from the observational period (93 patients, $93 \mathrm{yrs}$ ), both for the historical and GOL year, because during active AAU the chances of developing AAU in the other eye are very small. Subsequently, the period of being at risk for AAU was calculated for both study periods. If the start and/or stop date of the AAU were unknown, an AAU duration of 90 days was assumed ${ }^{35}$. Next, the number of AAU events per $100 \mathrm{PY}$ was reported for the historical and GOL year. Finally, the rate-ratio (events per years at risk), with standard error (SE) and 95\% CI was calculated, comparing the number of AAU per years at risk before the first TNFi and during GOL treatment.

The change in ASDAS during the study was analyzed using generalized estimating equation analysis. The change in other AS disease variables was evaluated using descriptive statistics for the comparisons between baseline and 12 months, using the McNemar's test, the paired sample $t$ tests, or the Wilcoxon signed-rank test, as appropriate. All analyses were performed on data available at the timepoint considered.

\section{RESULTS}

In total, 104 patients with AS were screened for eligibility, of whom 101 patients were enrolled (Figure 1). Eight patients were excluded from further analyses, as depicted in Figure 1. Consequently, 93 patients (92\%) were included, of whom demographic and baseline characteristics are presented in Table 1 . The patients were predominantly male $(65 \%)$, and $45 \%$ were TNFi-experienced and on average had used 1 (median 1; 1-2) TNFi before. For the TNFi-experienced

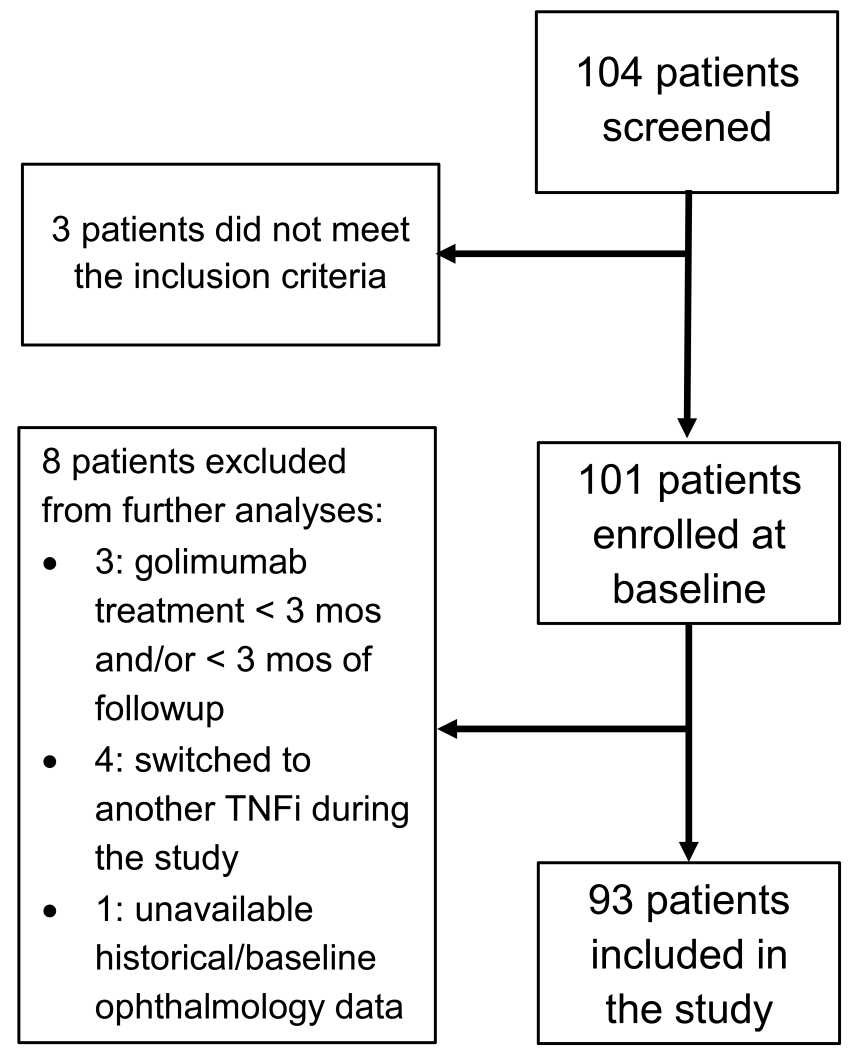

Figure 1. Flowchart depicting patient inclusion into the study. TNFi: tumor necrosis factor- $\alpha$ inhibitor.
Table 1. Patient characteristics at baseline $(\mathrm{n}=93)$.

\begin{tabular}{lc}
\hline Characteristics & Values \\
\hline Sex, male & $61(65)$ \\
Age, yrs & $44 \pm 13$ \\
Ethnicity, white & $90(97)$ \\
Weight, kg & $83 \pm 18$ \\
Body mass index, $\mathrm{kg} / \mathrm{m}^{2}$ & $26 \pm 4.8$ \\
Years since AS diagnosis & $7(1-18)^{*}$ \\
HLA-B27 status, positive & $69(74)^{* *}$ \\
History of AAU & $25(27)$ \\
History of psoriasis & $14(15)$ \\
History of IBD & $7(8)$ \\
Previous use of a TNF inhibitor & $42(45)$ \\
NSAID, current use & $71(76)$ \\
Immunosuppressive drugs, current use & $12(13)$ \\
DMARD & $10(11)$ \\
Systemic corticosteroids & $4(4)$ \\
\hline
\end{tabular}

Values are reported as $\mathrm{n}(\%$ of total), mean $( \pm \mathrm{SD})$, or median $(\mathrm{Q} 1-\mathrm{Q} 3)$. * Two patients had an unknown diagnosis date. ** The HLA-B27 status of 3 patients was missing. ${ }^{\dagger}$ Two patients used both a DMARD and systemic corticosteroids. DMARD: disease-modifying antirheumatic drug; NSAID: nonsteroidal antiinflammatory drug; AS: ankylosing spondylitis; AAU: acute anterior uveitis; IBD: inflammatory bowel disease; TNF: tumor necrosis factor.

patients, the median time since the year before the first TNFi was $5.2(2.3-7.4)$ years.

AAU attacks. Overall, $27 \%$ of the patients had a history of AAU. In the year before the first TNFi, 7 patients experienced a total of 10 AAU attacks (Table 2). At baseline, 5 patients had AAU (4 unilaterally and 1 bilaterally). Of those patients, 4 were TNFi-experienced. During GOL treatment, 2 new AAU attacks were reported by 2 patients, both HLA-B27-positive and with a history of AAU (but not in the year before the first TNFi). One was a TNFi-naive male who achieved the ASAS20 response criteria within a month, and the other was a TNFi-experienced female who maintained high disease activity.

Table 2. Acute anterior uveitis in the year before the first TNF inhibitor and during 1 year of golimumab treatment.

\begin{tabular}{|c|c|c|c|}
\hline & $\begin{array}{l}\text { Before the } \\
\text { First TNFi }\end{array}$ & $\begin{array}{c}\text { During } \\
\text { Golimumab TX }\end{array}$ & $\begin{array}{r}95 \% \mathrm{CI} \\
\mathrm{X}\end{array}$ \\
\hline Observational years $^{1}$ & 93 & 93 & \\
\hline Years at risk for a new $\mathrm{AAU}^{2}$ & 89.8 & 90.4 & \\
\hline No. patients with AAU & 7 & 2 & * \\
\hline No. AAU attacks & 10 & 2 & \\
\hline AAU attacks/100 years at risk ${ }^{3}$ & 11.1 & 2.2 & \\
\hline Rate-ratio of new AAU (95\% CI) & & 0.2 & $(0.04-0.91)$ \\
\hline
\end{tabular}

Values are reported as numbers, numbers per 100 patient years, and ratio with $95 \%$ CI. * Nonsignificant reduction. ${ }^{1}$ The total no. patient-years observed during the study. ${ }^{2}$ The no. observational years minus the period that AAU was present. ${ }^{3}$ The no. AAU attacks per 100 patient-years at risk for new AAU. AAU: acute anterior uveitis; TNFi: tumor necrosis factor inhibitor; TX: treatment.

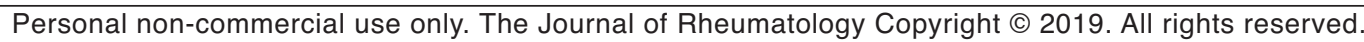


Consequently, the period of risk for a new AAU attack was calculated, both before TNFi and during GOL treatments. For 3 patients, the duration of AAU was unknown, all in the year before the first TNFi.

In the time before the initial TNFi, the period of risk was 89.8 years, in which $10 \mathrm{AAU}$ occurred, amounting to 11.1/100 PY. During GOL treatment the period of risk was 90.4 years, 2.2 AAU/100 PY. The rate-ratio for AAU after starting GOL was 0.20 (SE 0.77, 95\% CI 0.04-0.91; Table 2).

AS disease activity variables. At baseline, the median ASDAS disease activity score was 3.1 (2.4-4.1) and the CRP and ESR were elevated (respectively, $>8 \mathrm{mg} / \mathrm{l}$ and $>20$ $\mathrm{mm} / \mathrm{h}$ ) in respectively 30 and 33 percent of the patients. Additional disease variables at baseline and followup visits are presented in Table 3 .

After 3 months of treatment, $41 \%$ of the patients experienced a clinically important improvement $(\mathrm{p}<0.001)$ and $19 \%$ achieved a major improvement $(\mathrm{p}<0.001)$, and there was no significant difference between HLA-B27-positive and -negative patients. An ASAS20 treatment response was found in 36\% after 3 months ( $\mathrm{p}<0.001$ ), and $49 \%$ after 12 months ( $\mathrm{p}<0.001)$. Also, a statistically significant improvement was seen after 12 months of followup for most other variables of disease activity. The number of patients using NSAID or disease-modifying antirheumatic drugs (DMARD) after 12 months did not decrease significantly (respectively, from $76 \%$ to $72 \%$ and from $11 \%$ to $10 \%$ ).

Treatment compliance. Eventually, of the 93 patients, 17 $(18 \%)$, of whom $83 \%$ were male, discontinued treatment because of lack of treatment effect (8), adverse events (5), no treatment compliance (2), or a decision to stop study participation (2). For these patients, the time between the first registered GOL dose and the last GOL dose and the last study visit was, respectively, a median of 196 (84-251) and 228 (175-365) days. One patient was lost to followup, 280 days after the first GOL dose.

Adverse events. During the study, $80 \%$ of all initially enrolled patients (101) experienced at least 1 adverse event, mostly related to the usual side effects of TNFi, such as mild infections and injection site reactions. One new case of psoriasis was reported.

Twelve SAE were reported in 7 patients, of whom 5 were hospitalized. The SAE included infections (4 patients), exacerbation of ulcerative colitis, large intestinal ulcer hemorrhage, hypovolemic shock after hemorrhage, prostate cancer, cellulitis, bursitis, acute coronary syndrome, and cardiac failure. No deaths occurred.

\section{DISCUSSION}

Our study was the first, to our knowledge, to prospectively assess the occurrence of AAU during GOL treatment in AS, demonstrating a significant decrease in the number of AAU attacks. In addition, our study shows a good efficacy of GOL in a large group of patients with AS in a real-world setting, including both TNFi-naive and -experienced patients.

To date, only a few small, mostly retrospective, studies have reported on AS-related AAU during GOL treatment ${ }^{22,23,36}$. Also, those studies included patients with active AAU and mainly focused on the effect on ocular inflammatory variables. Complete remission of AAU was generally achieved rather rapidly in almost all patients, but the occurrence of AAU relapses was described in only a few small studies. Yazgan, et $a l^{22}$ and Calvo-Río, et $a l^{23}$ reported a change in AAU occurrence rate from 11 to 0 attacks in 11 months (11 patients with AS), and 5 to 0.5 attacks per person per year during 2 years of followup (15 patients with AS, respectively).

Table 3. Disease characteristics at baseline $(\mathrm{n}=93)$ and followup during golimumab treatment.

\begin{tabular}{|c|c|c|c|c|c|c|c|c|}
\hline \multirow[b]{2}{*}{ BASMI } & \multicolumn{2}{|c|}{ Baseline } & \multicolumn{2}{|c|}{3 Mos } & \multicolumn{2}{|c|}{$6 \mathrm{Mos}$} & \multicolumn{2}{|c|}{$12 \mathrm{Mos}$} \\
\hline & 0.6 & $(0.2-1.0)$ & 0.4 & $(0.2-0.8)$ & 0.4 & $(0.2-0.8)$ & 0.4 & $(0.2-0.8)$ \\
\hline MASES & 2 & $(0-4)$ & & & & & 0 & $(0-2)^{*}$ \\
\hline $\mathrm{CRP}, \mathrm{mg} / \mathrm{l}$ & 4 & $(2-11)$ & 3 & $(1-5)$ & 3 & $(1-4)$ & 3 & $(1-4)^{*}$ \\
\hline $\mathrm{ESR}, \mathrm{mm} / \mathrm{h}$ & 10 & $(5-24)$ & 4 & $(2-10)$ & 5 & (2-9) & 5 & $(2-9)^{*}$ \\
\hline BASDAI & 5.4 & $(3.8-6.5)$ & 3.9 & $(1.9-6.3)$ & 3.6 & $(1.5-6.0)$ & 3.3 & $(1.5-5.1)^{*}$ \\
\hline BAS-G, NRS & 6.5 & $(5.5-7.9)$ & 5.0 & $(3.0-7.0)$ & 4.5 & $(2.5-7.0)$ & 4.3 & $(1.5-6.5)^{*}$ \\
\hline Pain, NRS & 5.8 & $(3.5-7.1)$ & 3.0 & $(1.0-6.0)$ & 3.0 & $(1.0-6.0)$ & 2.5 & $(0.5-5.0) *$ \\
\hline Patient disease activity, NRS & 7 & $(5-8)$ & 4 & $(2-7)$ & 4 & $(1-6)$ & 3 & $(1-6)^{*}$ \\
\hline Physician disease activity, NRS & 6 & $(4-7)$ & 2 & $(1-4)$ & 2 & $(1-3)$ & 2 & $(1-3)^{*}$ \\
\hline ASQoL & 9 & $(4-13)$ & 6 & $(1-11)$ & 6 & $(1-11)$ & 4 & $(1-10)^{*}$ \\
\hline ASAS20 responders & & & 29 & $(36)$ & 34 & $(45)$ & 39 & $(49)^{*}$ \\
\hline
\end{tabular}

Values are reported as $\mathrm{n}(\%$ of total $)$, mean $( \pm \mathrm{SD})$, or median $(\mathrm{Q} 1-\mathrm{Q} 3) . *$ Significant change $(\mathrm{p}<0.01)$ compared to baseline. ASDAS: Ankylosing Spondylitis Disease Activity Score; ASQoL: AS Quality of Life questionnaire; CRP: C-reactive protein; BASDAI: Bath Ankylosing Spondylitis Disease Activity Index; BASFI: Bath AS Functional Index; BAS-G: Bath AS Global score; BASMI: Bath AS Metrology Index; ESR: erythrocyte sedimentation rate; MASES: Maastricht Ankylosing Spondylitis Enthesitis Score; NRS: numerical rating scale; ASAS: Assessment of Spondyloarthritis international Society (guidelines). 
In our setting, patients with AS were included regardless of a history of AAU, and thus the number of AAU attacks in the year before the initial TNFi appeared to be relatively low. In AS, some patients will experience only 1 AAU, while others have frequent recurrences ${ }^{11}$. In studies with TNFi-naive AS populations, the average yearly AAU incidence varies substantially, with an overall AAU flare rate of 15.6/100 PY reported in a metaanalysis ${ }^{1,12,13}$. In our study, an AAU incidence of 11.1/100 PY was found. This difference may be caused by a relatively lower prevalence of HLA-B27 positivity in our study, although the overall prevalence of AAU was comparable with other studies. Nevertheless, our current study did show a significant decrease in the AAU rate-ratio during GOL treatment. Also, and even more important, this occurred even though almost half of the patients were TNFi-experienced, while TNFi switchers have a lower chance of response on the next $\mathrm{TNFi}^{37,38}$. Moreover, the patients who recently experienced an AAU, either at baseline or in the previous year (for TNFi-naive patients), did not develop a new AAU during GOL. These findings suggest a favorable effect of GOL on the occurrence risk of AAU in AS.

The secondary objective was to assess the efficacy of GOL on AS disease activity. Data from the GO-RAISE phase III controlled trial show higher response rates, reporting ASAS20 response in over $70 \%$ after 52 weeks ${ }^{21,39}$. Another phase III randomized controlled trial in China reported an ASAS20 response in $50 \%$ at Week $14^{40}$. However, those studies were not performed in a daily clinical practice setting and only included TNFi-naive patients with generally higher baseline disease activity (baseline BASDAI scores of 6.8 and 6.5 , respectively $)^{21,40}$. These characteristics are associated with a higher chance of a good clinical response ${ }^{37,38,41}$. Additionally, in our study, relatively more women were included (35\% vs $28 \%$ and $17 \%$ ); women are associated with a lower clinical response to $\mathrm{TNFi}^{42}$. The occurrence of treatment discontinuation and the frequency and type of adverse events, including SAE, were similar to other studies on $\mathrm{TNFi}^{21,39,40,43,44}$.

To interpret the results of the current study correctly, a few aspects should be taken into consideration. First, the possible influence of a previous TNFi in TNFi-experienced patients was eliminated as much as possible by a design in which the patients were their own control. In the case of TNFi-experienced patients, the year of historical control of AAU was up to 5 years before the start of GOL, whereas in TNF-naive patients, the occurrence of AAU was collected more recently, in the year before start of GOL. In a previous study, it was demonstrated that the AAU occurrence rate seems higher in patients who recently experienced an AAU. Therefore, the decrease in AAU occurrence could be even higher than was shown in our study, because in our study several patients experienced an AAU attack within the year before the start of $\mathrm{GOL}^{13}$. Data were not collected on AAU occurrence during treatment with the previous TNFi, so it is unclear whether this aspect of the study design induced bias for the TNFi-experienced patients.

Second, in AAU occurrence rate analysis, it was assumed that a patient with active AAU was at that moment not at risk for a new AAU attack, which could be debated. However, simultaneous AAU in the other eye does not happen often in AS, although this might be different in other regions ${ }^{45}$. Calculating the AAU occurrence rate for the period that a patient was actually at risk for a new AAU, instead of for the total observational time, does give a more accurate approximation of the risk of new attacks.

Third, during the study, 12 patients were concomitantly treated with an immunosuppressive drug. We do not expect that the concomitant use of a DMARD has affected the results because the influence of DMARD on the AS disease activity has proven to be very small and the evidence of its effect on the AAU occurrence in AS is limited. Further, the number of patients using a DMARD during GOL treatment was even lower than in the control year (10 vs 13 patients). Systemic corticosteroids could have influenced only the AAU occurrence for 1 patient, because the other already used corticosteroids in the control year. The 2 patients who used both corticosteroids and a DMARD during the study had chronic uveitis and were therefore not taken into account as being at risk for a new AAU.

Because of the overall low incidence of AAU, it was not possible to compare the change in the occurrence of AAU in subgroups, such as TNFi-experienced versus -naive patients, patients with a high versus low disease activity, or patients who recently experienced AAU. For future research we recommend including a population with a higher prevalence of AAU and to collect data on AAU during previously used TNFi in TNFi-experienced patients. Additionally, a longer followup period would provide the opportunity to study the longterm effect of GOL on AAU. Lastly, although our study was not powered to assess the efficacy of GOL as a primary objective, GOL appeared to be beneficial for the majority of the study population. We do think this is a clinically relevant outcome that should be considered in future research because the real-world setting enhances the usability of the study results in daily practice.

From this first prospective followup study on the occurrence rate of AAU during GOL treatment in AS, it can be concluded that a significant decrease in the incidence of AAU was seen during GOL treatment in daily clinical practice. Also, GOL was well tolerated and led to an improvement in the AS disease activity in the majority of the patients.

\section{ACKNOWLEDGMENT}

The current study was presented during a poster presentation at the 2016 conference of the European League Against Rheumatism.

\section{REFERENCES}

1. Braun J, Baraliakos X, Listing J, Sieper J. Decreased incidence of Personal non-commercial use only. The Journal of Rheumatology Copyright @ 2019 . All rights reserved. 
anterior uveitis in patients with ankylosing spondylitis treated with the anti-tumor necrosis factor agents infliximab and etanercept. Arthritis Rheum 2005;52:2447-51.

2. Stolwijk C, van Tubergen A, Castillo-Ortiz JD, Boonen A. Prevalence of extra-articular manifestations in patients with ankylosing spondylitis: a systematic review and meta-analysis. Ann Rheum Dis 2015;74:65-73.

3. Zeboulon N, Dougados M, Gossec L. Prevalence and characteristics of uveitis in the spondyloarthropathies: a systematic literature review. Ann Rheum Dis 2008;67:955-9.

4. O'Rourke M, Haroon M, Alfarasy S, Ramasamy P, FitzGerald O, Murphy CC. The effect of anterior uveitis and previously undiagnosed spondyloarthritis: results from the DUET cohort. J Rheumatol 2017;44:1347-54.

5. Loh AR, Acharya NR. Incidence rates and risk factors for ocular complications and vision loss in HLA-B27-associated uveitis. Am J Ophthalmol 2010;150:534-42 e2.

6. Gritz DC, Schwaber EJ, Wong IG. Complications of uveitis: the Northern California Epidemiology of Uveitis Study. Ocul Immunol Inflamm 2018;26:584-94.

7. Linssen A, Rothova A, Valkenburg HA, Dekker-Saeys AJ, Luyendijk L, Kijlstra A, et al. The lifetime cumulative incidence of acute anterior uveitis in a normal population and its relation to ankylosing spondylitis and histocompatibility antigen HLA-B27. Invest Ophthalmol Vis Sci 1991;32:2568-78.

8. Khera TK, Dick AD, Nicholson LB. Mechanisms of TNF $\alpha$ regulation in uveitis: focus on RNA-binding proteins. Prog Retin Eye Res 2010;29:610-21.

9. Pérez-Guijo V, Santos-Lacomba M, Sánchez-Hernández M, Castro-Villegas Mdel C, Gallardo-Galera JM, Collantes-Estévez E. Tumour necrosis factor-alpha levels in aqueous humour and serum from patients with uveitis: the involvement of HLA-B27. Curr Med Res Opin 2004;20:155-7.

10. Maxwell LJ, Zochling J, Boonen A, Singh JA, Veras MM, Tanjong Ghogomu E, et al. TNF-alpha inhibitors for ankylosing spondylitis. Cochrane Database Syst Rev 2015:CD005468.

11. Guignard S, Gossec L, Salliot C, Ruyssen-Witrand A, Luc M, Duclos M, et al. Efficacy of tumour necrosis factor blockers in reducing uveitis flares in patients with spondylarthropathy: a retrospective study. Ann Rheum Dis 2006;65:1631-4.

12. van Denderen JC, Visman IM, Nurmohamed MT, Suttorp-Schulten MS, van der Horst-Bruinsma IE. Adalimumab significantly reduces the recurrence rate of anterior uveitis in patients with ankylosing spondylitis. J Rheumatol 2014;41:1843-8

13. Rudwaleit M, Rodevand E, Holck P, Vanhoof J, Kron M, Kary S, et al. Adalimumab effectively reduces the rate of anterior uveitis flares in patients with active ankylosing spondylitis: results of a prospective open-label study. Ann Rheum Dis 2009;68:696-701.

14. van der Heijde D, Dougados M, Landewé R, Sieper J, Maksymowych WP, Rudwaleit M, et al. Sustained efficacy, safety and patient-reported outcomes of certolizumab pegol in axial spondyloarthritis: 4-year outcomes from RAPID-axSpA. Rheumatology 2017;56:1498-509.

15. Lim LL, Fraunfelder FW, Rosenbaum JT. Do tumor necrosis factor inhibitors cause uveitis? A registry-based study. Arthritis Rheum 2007;56:3248-52.

16. Lie E, Lindström U, Zverkova-Sandström T, Olsen IC, Forsblad-d'Elia H, Askling J, et al. Tumour necrosis factor inhibitor treatment and occurrence of anterior uveitis in ankylosing spondylitis: results from the Swedish biologics register. Ann Rheum Dis 2017;76:1515-21.

17. Wendling D, Joshi A, Reilly P, Jalundhwala YJ, Mittal M, Bao Y. Comparing the risk of developing uveitis in patients initiating anti-tumor necrosis factor therapy for ankylosing spondylitis: an analysis of a large US claims database. Curr Med Res Opin
2014;30:2515-21.

18. Wu D, Guo YY, Xu NN, Zhao S, Hou LX, Jiao T, et al. Efficacy of anti-tumor necrosis factor therapy for extra-articular manifestations in patients with ankylosing spondylitis: a meta-analysis. BMC Musculoskelet Disord 2015;16:19.

19. van der Horst-Bruinsma IE, Nurmohamed MT. Management and evaluation of extra-articular manifestations in spondyloarthritis. Ther Adv Musculoskelet Dis 2012;4:413-22.

20. Sampaio-Barros PD, van der Horst-Bruinsma IE. Adverse effects of TNF inhibitors in SpA: are they different from RA? Best Pract Res Clin Rheumatol 2014;28:747-63.

21. Inman RD, Davis JC Jr., Heijde D, Diekman L, Sieper J, Kim SI, et al. Efficacy and safety of golimumab in patients with ankylosing spondylitis: results of a randomized, double-blind,

placebo-controlled, phase III trial. Arthritis Rheum 2008; 58:3402-12.

22. Yazgan S, Celik U, Isik M, Yesil NK, Baki AE, Sahin H, et al. Efficacy of golimumab on recurrent uveitis in HLA-B27-positive ankylosing spondylitis. Int Ophthalmol 2017;37:139-45.

23. Calvo-Río V, Blanco R, Santos-Gómez M, Rubio-Romero E, Cordero-Coma M, Gallego-Flores A, et al. Golimumab in refractory uveitis related to spondyloarthritis. Multicenter study of 15 patients. Semin Arthritis Rheum 2016;46:95-101.

24. van der Linden S, Valkenburg HA, Cats A. Evaluation of diagnostic criteria for ankylosing spondylitis. A proposal for modification of the New York criteria. Arthritis Rheum 1984;27:361-8.

25. Braun J, Pham T, Sieper J, Davis J, van der Linden S, Dougados M, et al. International ASAS consensus statement for the use of anti-tumour necrosis factor agents in patients with ankylosing spondylitis. Ann Rheum Dis 2003;62:817-24.

26. Garrett S, Jenkinson T, Kennedy LG, Whitelock H, Gaisford P, Calin A. A new approach to defining disease status in ankylosing spondylitis: the Bath Ankylosing Spondylitis Disease Activity Index. J Rheumatol 1994;21:2286-91.

27. van der Heijde D, Lie E, Kvien TK, Sieper J, Van den Bosch F, Listing J, et al. ASDAS, a highly discriminatory ASAS-endorsed disease activity score in patients with ankylosing spondylitis. Ann Rheum Dis 2009;68:1811-8.

28. Calin A, Garrett S, Whitelock H, Kennedy LG, O’Hea J, Mallorie P, et al. A new approach to defining functional ability in ankylosing spondylitis: the development of the Bath Ankylosing Spondylitis Functional Index. J Rheumatol 1994;21:2281-5.

29. Jones SD, Steiner A, Garrett SL, Calin A. The Bath Ankylosing Spondylitis Patient Global Score (BAS-G). Br J Rheumatol 1996;35:66-71.

30. Doward LC, Spoorenberg A, Cook SA, Whalley D, Helliwell PS, Kay LJ, et al. Development of the ASQoL: a quality of life instrument specific to ankylosing spondylitis. Ann Rheum Dis 2003;62:20-6.

31. Heuft-Dorenbosch L, Spoorenberg A, van Tubergen A, Landewé R, van ver Tempel H, Mielants $H$, et al. Assessment of enthesitis in ankylosing spondylitis. Ann Rheum Dis 2003;62:127-32.

32. Jenkinson TR, Mallorie PA, Whitelock HC, Kennedy LG, Garrett SL, Calin A. Defining spinal mobility in ankylosing spondylitis (AS). The Bath AS Metrology Index. J Rheumatol 1994;21:1694-8.

33. Machado P, Landewe R, Lie E, Kvien TK, Braun J, Baker D, et al. Ankylosing Spondylitis Disease Activity Score (ASDAS): defining cut-off values for disease activity states and improvement scores. Ann Rheum Dis 2011;70:47-53.

34. Anderson JJ, Baron G, van der Heijde D, Felson DT, Dougados M. Ankylosing spondylitis assessment group preliminary definition of short-term improvement in ankylosing spondylitis. Arthritis Rheum 2001;44:1876-86.

35. Braakenburg AM, de Valk HW, de Boer J, Rothova A. Human leukocyte antigen-B27-associated uveitis: long-term follow-up and

Personal non-commercial use only. The Journal of Rheumatology Copyright (c) 2019. All rights reserved. 
gender differences. Am J Ophthalmol 2008;145:472-9.

36. Calvo-Río V, de la Hera D, Blanco R, Beltran-Catalan E, Loricera J, Canal $\mathrm{J}$, et al. Golimumab in uveitis previously treated with other anti-TNF-alpha drugs: a retrospective study of three cases from a single centre and literature review. Clin Exp Rheumatol 2014;32:864-8.

37. Glintborg B, Ostergaard M, Krogh NS, Tarp U, Manilo N, Loft AG, et al. Clinical response, drug survival and predictors thereof in 432 ankylosing spondylitis patients after switching tumour necrosis factor alpha inhibitor therapy: results from the Danish nationwide DANBIO registry. Ann Rheum Dis 2013;72:1149-55.

38. Deodhar A, Yu D. Switching tumor necrosis factor inhibitors in the treatment of axial spondyloarthritis. Semin Arthritis Rheum 2017;47:343-50.

39. Deodhar A, Braun J, Inman RD, van der Heijde D, Zhou Y, Xu S, et al. Golimumab administered subcutaneously every 4 weeks in ankylosing spondylitis: 5-year results of the GO-RAISE study. Ann Rheum Dis 2015;74:757-61.

40. Bao C, Huang F, Khan MA, Fei K, Wu Z, Han C, et al. Safety and efficacy of golimumab in Chinese patients with active ankylosing spondylitis: 1-year results of a multicentre, randomized, double-blind, placebo-controlled phase III trial. Rheumatology 2014;53:1654-63.
41. Arends S, van der Veer E, Kallenberg CG, Brouwer E, Spoorenberg A. Baseline predictors of response to TNF-alpha blocking therapy in ankylosing spondylitis. Curr Opin Rheumatol 2012;24:290-8.

42. van der Horst-Bruinsma IE, Zack DJ, Szumski A, Koenig AS. Female patients with ankylosing spondylitis: analysis of the impact of gender across treatment studies. Ann Rheum Dis 2013;72:1221-4.

43. Braun J, Deodhar A, Inman RD, van der Heijde D, Mack M, Xu S, et al. Golimumab administered subcutaneously every 4 weeks in ankylosing spondylitis: 104-week results of the GO-RAISE study. Ann Rheum Dis 2012;71:661-7.

44. Iannone F, Santo L, Anelli MG, Bucci R, Semeraro A, Quarta L, et al. Golimumab in real-life settings: 2 years drug survival and predictors of clinical outcomes in rheumatoid arthritis, spondyloarthritis, and psoriatic arthritis. Semin Arthritis Rheum 2017;47:108-14.

45. Yang P, Wan W, Du L, Zhou Q, Qi J, Liang L, et al. Clinical features of HLA-B27-positive acute anterior uveitis with or without ankylosing spondylitis in a Chinese cohort. Br J Ophthalmol 2018;102:215-9. 